\title{
ELOGIO HISTÓRICO DO ACADÉMICO EMÉRITO ILÍDIO MELO PERES DO AMARAL, FEITO PELO SENHOR JORGE MANUEL BARBOSA GASPAR
}

JORGE GASPAR ${ }^{1}$

Academia das Ciências de Lisboa, 27 de Março de 2014

\author{
Caríssimo Confrade Emérito Ilídio do Amaral \\ Senhores Confrades \\ Minhas Senhoras e Meus Senhores
}

Constitui para mim uma honra e uma grande alegria ocupar a cadeira (28L) que Ilídio do Amaral inaugurou e a que portanto deu nome e conteúdo, na secção das Letras desta Academia das Ciências. Sou aluno de Ilídio do Amaral há quase 54 anos e tenho plena consciência das dificuldades que se me colocam numa função que resume muito do espírito das academias científicas: a necessária continuidade científica, social e cultural do trabalho académico.

A maior dessas dificuldades decorre de ao cabo de mais de meio século de aprendizagem e colaboração, ainda hoje me surpreender com as produções que o confrade Ilídio do Amaral nos vai oferecendo com regularidade.

À medida que ia elaborando este texto que hoje vos apresento, aumentavam as dificuldades de inclusão das atividades desenvolvidas por Ilídio do Amaral pertinentes para esta função. De facto, cada entrada que me parecia adequada para inserir as ações do confrade, justificava plenamente uma sessão autónoma: o académico, o geógrafo, o gestor universitário, o curador da coisa pública, o incansável investigador, o pedagogo, o facilitador tolerante e eficaz.

Ilídio Melo Peres do Amaral nasceu em Luanda em 1926, nas Ingombotas (Freguesia de Nossa Senhora do Carmo), numa família angolana mestiça, Sotto Mayor do lado materno e Amaral Gurgel do lado paterno. Nessa cidade fez os seus primeiros estudos - ensino primário e secundário. Ainda antes de iniciar a sua carreira como geógrafo e assistente universitário, foi empregado bancário em Lisboa, no Banco Português do Atlântico, e em Luanda, no Banco Comercial de Angola, onde foi responsável pelos Serviços de Comércio Externo e de Garantias Bancárias.

Na Universidade de Lisboa, concluiu a licenciatura em Geografia em 1956, o doutoramento em 1964, a agregação/professor extraordinário em 1968 e chegou a Professor Catedrático em 1969. Nesta

1 Professor Emérito do Instituto de Geografia e Ordenamento do Território da Universidade de Lisboa, e Investigador Efetivo do Centro de Estudo Geográficos, Rua Branca Edmée Marques, 1600-276 Lisboa, Portugal. E-mail: jorgegaspar@campus.ul.pt 
Universidade foi membro do Senado, Vice-Reitor e Reitor. Como o próprio refere nas suas notas bibliográficas, a revista Pública do jornal Público, sublinhou o facto de ser então, “...o único professor catedrático de origem africana alguma vez a assumir o cargo de Reitor em Portugal”.

\section{O ACADÉMICO}

O ilustre académico Ilídio Melo Peres do Amaral é acima de tudo o exemplo, a personificação do ideal académico: "Nisi utile est quod facimus, stulta est gloria". (Se não for útil o que fizermos, a glória será vã).

Da atividade académica de Ilídio do Amaral pode dizer-se que é a de um trabalhador inspirado e meticuloso, com a ambição de saber e dar a conhecer.

Desprendido em relação a honrarias, mesmo quando inerentes ao seu desempenho e na sequência lógica do seu labor: nunca ocupou qualquer cargo na Academia.

Mas o mesmo se passou no Instituto de Geografia e no Centro de Estudos Geográficos, da Universidade de Lisboa, de que foi o verdadeiro esteio ao longo de duas décadas.

Ilídio Melo Peres do Amaral foi eleito Sócio Correspondente da Academia das Ciências em 15 de Julho de 1976 e desde então não cessou um percurso de académico dedicado aos grandes objetivos da instituição, mormente através da assiduidade aos atos académicos, apresentação de comunicações e intervenções a propósito de comunicações de confrades.

Assim, em 1988, passava naturalmente a Efetivo e recorrentemente viria a colaborar e a representar a Academia. Neste particular, relevam-se a participação ativa no Programa Towards Young Academies across Europe. Sharing Experiences and Building Capacities, que se efetuou em Madrid, no Instituto de Espanha, com o patrocínio da ALLEA - All European Academies - European Federation of Academies of Sciences and Humanities.

De grande alcance para a Academia das Ciências de Lisboa foi a sua proposta de 2001, por solicitação do então presidente Senhor Professor Adriano Moreira, de organização da 7a Secção do Classe de Letras, "Sociologia e outras Ciências Sociais", para o que estabeleceu contatos com os futuros 10 sócios correspondentes e preparou os respetivos processos, que foram submetidos para votação do Plenário de Sócio Efetivos.

Também por convite do Presidente Senhor Professor Adriano Moreira levou a cabo com grande empenho e sucesso a "representação adequada de Académicos Correspondentes dos Países Africanos de Língua Oficial Portuguesa. Foi assim que um conjunto de personalidades de grande prestígio internacional, cientistas, escritores e artistas, de Angola, Moçambique, Cabo Verde, Guiné-Bissau e São Tomé e Príncipe, vieram a integrar a nossa Academia. Participou ainda na proposta e eleição de outros grandes vultos, como José Ramos Horta, então Presidente da República de Timor Leste, de Nelson Mandela e do Príncipe Aga Khan. Patrocinou também a entrada de dois especialistas em História de Angola e de África, a alemã Beatrix Heintze e o norte-americano Calder Miller.

Ilídio do Amaral levou a cabo várias investigações no domínio da História no acervo bibliográfico e documental da Academia das Ciências, que originaram comunicações, conferências, bem como publicações, algumas no âmbito da Academia, outras através de outras entidades e algumas até por sua iniciativa e impressas à sua custa.

Assim, em 2003 publicou As Academias das Ciências na Contextura da Globalização, em que estuda 77 Academias das Ciências da Europa, analisando os respetivos comportamentos face à globalização, dando particular ênfase às redes nacionais e continentais que se desenvolveram. Mas o estudo não ficou pelas análises, apresentando propostas de medidas necessárias para a modernização e atualização das Academias, mormente da Academia das Ciências de Lisboa. Este trabalho foi revisto em 2008 (Amaral, 2008a). 
Outro foco da atividade académica de Ilídio do Amaral tem sido a chamada de atenção para a necessidade de uma boa História da Academia das Ciências de Lisboa que seja, e utilizo as suas próprias palavras, "dignificadora de uma instituição que existe há mais de duas centúrias muito ricas em acontecimentos e que é detentora de um espólio valiosíssimo carecido de condições financeiras e humanas favoráveis para a sua manutenção, o seu estudo e divulgação". Como contributo, apresentou, em 2010, as "Nótulas históricas sobre os primeiros tempos da Academia das Ciências de Lisboa" (Amaral, 2012b), em que anuncia "um livro em elaboração", que já tem o título provisório de A Fundação da Academia das Ciências de Lisboa no contexto das ideias da Europa de meados do século XVIII a meados do século XIX.

$\mathrm{Na}$ continuada tarefa de chamar a atenção para o valioso património bibliográfico da Academia das Ciências de Lisboa, Ilídio do Amaral peregrinou pelo legado de Frei Manuel do Cenáculo, sob o patrocínio estimulante de mestre José Vitorino de Pina Martins:

"Quando o incunábulo augustiniano - [referência à Cidade de Deus de Santo Agostinho oferecida pelo Prof. José Vitorino de Pina Martins à Academia das Ciências de Lisboa] se encontrava entre os meus livros numa estante onde ele dialogava com os Opera omnia de Pico della Mirandola (Bolonha, 1496), eu recorria frequentemente à sua leitura por amor librorum ou por imposição da minha curiosidade, na Academia das Ciências, o meu incunábulo passou a ficar numa sala hermeticamente fechada, onde se encontram os livros valiosos, ou seja o que os Franceses chamam a Réserve Précieuse. Mas a reserva Preciosa ficou realmente... de reserva. Os ilustres académicos não estão hoje voltados para o passado. Os científicos olham, como está bem de ver, para o futuro. Muitos dos letrados não amam de facto o que chamam, num jargon moderno, a cultura livresca... E eis como, deste modo, os incunábulos ficam condenados a pernoitar no escuro intangível da Reserva Preciosa" (excerto retirado de J. V. de Pina Martins, "As queixas de um incunábulo (Veneza, 1475) esquecido e abandonado" em pp. 225-230 de História de Livros para a História do Livro. Lisboa, Fundação Calouste Gulbenkian, 2007).” (Amaral, 2012c, p.9).

Dessa peregrinação resultaram notas, comentários e informações de grande alcance, reunidas na publicação As Bíblias e outras Raridades das Colecções de Frei Manuel do Cenáculo. Da sua existência na Biblioteca da Academia das Ciências de Lisboa. Além de abrir novas pistas para o conhecimento da personalidade poliédrica que foi o antigo Bispo de Beja e Arcebispo de Évora, aponta um estimulante conjunto de considerações sobre bíblias, mormente sobre a Bíblia de Johannes Gutenberg. Mas o foco das reflexões centra-se na Bíblia de Mogúncia ou Moguntina, de 1462, que foi de Frei Manuel do Cenáculo e hoje faz parte da "Reserva Preciosa" da Academia das Ciências de Lisboa. A análise bibliológica da obra permite-lhe o estabelecimento de diálogo com abordagens antecedentes, nomeadamente as de J. V. Pina Martins (Martins, 2007) e de Artur Anselmo (Anselmo, 1997).

Também José Correia da Serra foi objeto das pesquisas de Ilídio do Amaral no âmbito do património documental da Academia das Ciências de Lisboa. Desse labor já resultaram dois livros, publicados sob o título geral de Estudos Preliminares de Inéditos Juvenis de José Correia da Serra: o primeiro em 2012 - A propósito do Catalogue Raisonné des Voyageurs de ma Bibliothéque (1769) e o segundo, em 2013 - A propósito dos Zibaldone di Materie Diverse I a IV (1767). (Amaral, 2012a; Amaral, 2013a).

\section{O GEÓGRAFO}

A descoberta e confirmação da vocação de geógrafo terá sido fortemente inspirada no convívio científico e humano com Mestre Orlando Ribeiro (Amaral, 1981a; Amaral, 1981d Amaral, 1984c; Amaral, 1997c; Amaral, 2008b). 
Claro que tal só foi possível graças ao seu espírito geométrico e sentido do rigor, ao gosto pelo campo e pelo trabalho de campo, que exercita como método fundamental nas suas pesquisas geográficas, em particular nas de geomorfologia.

Paulatinamente leva a cabo uma obra extensa e multifacetada, plena de temas de interesse, sobretudo para a Geografia, mas não só.

Por isso é muito difícil fazer uma seleção, no entanto, depois de uma aturada revisitação às obras de Ilídio do Amaral, mais demorada do que inicialmente previa - por vezes parei na apreciação/avaliação de mais de meio século do meu próprio percurso de geógrafo, assinalando com exaltação momentos gratificantes; outras vezes a descobrir novas facetas na obra de Ilídio do Amaral, de que eu tinha passado ao lado, por distração ou tão só por falta de amadurecimento para ver.

Ainda assim, acabei por "escolher" três momentos que marcam o percurso do Geógrafo:

A - Santiago - A Terra e os Homens, 1964

B - Luanda - estudo da Geografia Urbana, 1968

C - Duas abordagens muito recentes (2012/2013) dos fenómenos interligados da urbanização e da globalização...: a partir de duas conferências, uma na Universidade Católica, em Lisboa, outra na Universidade de Cabo Verde.

\section{A - Santiago - A Terra e os Homens}

Este estudo constituiu a dissertação de doutoramento em Geografia pela Universidade de Lisboa, apresentada e defendida em 1964, e publicado, numa primeira edição, esgotada, pela Junta de Investigações do Ultramar, nas suas Memórias ( $N^{\circ}$ 48, segunda série) tendo tido nova edição em 2007, promovida por cinco instituições, a que o percurso de Ilídio do Amaral ficou associado de diferentes maneiras: a Associação das Universidades de Língua Portuguesa, o Centro de Estudos Geográficos da Universidade de Lisboa, o Instituto de Investigação Científica Tropical, a Universidade do Algarve e a Universidade de Cabo Verde.

Trata-se de uma excelente monografia de Geografia regional na linha da melhor escola francesa, de que a escola portuguesa foi uma prestigiada herdeira. Num e noutro caso, verifica-se no pós-guerra uma passagem do estudo dos espaços metropolitanos para os domínios coloniais. Podem apresentar-se como paradigmas da abordagem em territórios insulares coloniais, no caso francês, as teses de doutoramento de Guy Lasserre, sobre a Ilha de Guadalupe (Lasserre, 1961) e de Defos du Rau sobre a Ilha Reunião (Defos du Rau, 1960) e no caso português, o estudo de Orlando Ribeiro sobre a Ilha do Fogo (Ribeiro, 1954), as dissertações de doutoramento de Francisco Tenreiro, sobre a Ilha de São Tomé (Tenreiro, 1961) e de Ilídio do Amaral sobre Santiago (Amaral, 1964).

Sem abandonar o modelo clássico da Geografia Regional francesa, Ilídio do Amaral por um lado promove atualizações decorrentes dos avanços das ciências geográficas, mormente as do mundo anglo-saxónico e, por outro lado, adequa o exercício científico à realidade daquele espaço concreto. Daqui resultam a um tempo capítulos de grande atualidade, como os que dedica ao clima - questão maior na Geografia de Cabo Verde, e à Geomorfologia, domínio em que o autor é um dos grandes especialistas da nossa Universidade, e capítulos fundamentais nas componentes sociais e económica, inescapáveis para quem recorre ao trabalho de campo como método privilegiado.

Mas a atualização que o autor promove no âmbito da Geografia Regional ficou expressa na abordagem dos aspetos da vida de relação e na preocupação com a aplicação dos conhecimentos que a sua investigação podia oferecer aos decisores políticos. Preocupações que são sintetizadas no final do último capítulo (Perspetivas económicas) num ponto a que chamava "Em torno dos problemas da ilha" e nas Conclusões: "A tentativa de soluções tiradas das possibilidades locais conduz portanto a certo pessimismo, e mesmo a um sentimento de impotência, sugeridos pela simples apresentação dos problemas. 
Razoáveis se por acaso a população não aumentasse, não se adaptariam ao acréscimo que, inevitavelmente, haviam de promover. Não só a realização simultânea dessa variedade de soluções levaria à dispersão de esforços, como exigiria tal soma de créditos, para resultados tão medíocres, que é legítimo exitar antes de escolher." (Amaral, 1964, 368). "E este é o grande problema das ilhas, mesmo daquelas que vão experimentando certos progressos: a INCERTEZA de se poderem manter, sem este auxílio, no quadro dos seus próprios recursos." (Amaral, 1964, p. 373).

\section{B - Luanda - Estudo de Geografia Urbana}

Luanda - estudo de Geografia Urbana, concluído em 1967 e publicado no ano seguinte (Amaral, 1968b), é um trabalho amadurecido ao longo de um percurso de 12 anos, tempo transcorrido desde a elaboração da dissertação de licenciatura (São Paulo de Assunção de Luanda, FLUL, 1956), período em que Ilídio do Amaral além de pesquisas intensas no âmbito da Geomorfologia e da Geografia Regional, dedicou continuado interesse ao Urbanismo de África, com destaque para os estudos sobre Luanda, Rede Urbana de Angola e Johannesburgo (Amaral, 1957; Amaral, 1959; Amaral, 1961; Amaral, 1962; Amaral, 1966).

Este estudo de Geografia Urbana é ainda hoje uma das mais penetrantes leituras do "processo dinâmico da evolução urbana" de uma cidade de África, um encaminhamento que vai da leitura do sítio à "expansão urbana e seus problemas", resolvendo-se numa síntese conclusiva, em que se apontam como problemas maiores a macrocefalia face ao território angolano, com patente primazia (primate-city) no contexto da rede urbana de Angola. Assim, temos um diagnóstico, enriquecido por uma visão prospetiva, cuja justeza o tempo confirmou: "Cidade dinâmica, de crescimento atual explosivo, onde se concentram o poder e o capital, não tendo gerado uma região urbana próxima, sujeitou, todavia, à sua dependência uma área vasta. Neste contraste tem Luanda um dos seus traços mais originais e delicados, de marcada singularidade no campo da génese e evolução das cidades." (Amaral, 1968b,129). Este é último parágrafo do livro e foi escrito em 1967 e poderia sintetizar o tema de um colóquio, de uma conferência, sobre os problemas atuais e futuros das capitais dos espaços intertropicais. Pensando nessa eventualidade, somos tentados a lançar desde já uma questão para um debate: e poderia ter sido de outra maneira?

Procuro ainda uma resposta para a questão de saber como foi possível um período tão conturbado como o dos anos 60, em Angola, elaborar uma obra tão serena, profunda, assertiva e que resiste ao tempo, ao ponto de ser hoje um instrumento fundamental para ler Luanda e o Urbanismo não só em Angola, como em África.

O profundo conhecimento daquelas realidades, o recurso à melhor teoria disponível nos saberes geográficos nos anos 1960 (Ilídio do Amaral compulsou a bibliografia mais atualizada, disponível em cinco idiomas) e o necessário trabalho de campo, explicam em boa medida o sucesso.

\section{C - Duas abordagens muito recentes (2012/2013) dos fenómenos interligados da urbanização e da globalização}

As Cidades: símbolos da Associação de Política, Economia e Cultura. Base para uma sessão com debate, curso de pós-graduação em Urbanismo U.C.P. 56 p. policopiadas, (Amaral, 2012d).

Assisti com emoção e proveito a esta sessão de seminário, conferência seguida de debate, em que participaram alunos e professores e teve a moderação do diretor do curso, o saudoso confrade Manuel da Costa Lobo. Ilídio do Amaral após uma breve mas estimulante síntese sobre a evolução das cidades e da urbanização, centrou-se nas grandes questões que se colocam hoje às cidades nas suas dimensões política e cultural, dando particular enfase aos problemas da sustentabilidade, nas componentes económica, social e ambiental. 
Cidades na África Subsariana no século XXI, como partes do Sul Global (Amaral, 2013b).

Na Conferência da Praia, 2013, Ilídio do Amaral começou por abordar o conceito de Sul global e sua pertinência quer para a questão do desenvolvimento, quer para a questão do Urbanismo e, em particular, para o entendimento das cidades.

Para o efeito apoia-se numa bibliografia muito diversificada, abrangendo todo o leque das ciências sociais, técnicas e artes pertinentes para a melhor dilucidação do fenómeno. A apresentação das notas e comentários dessa bibliografia constituem como que um Atlas e um roteiro através das várias dimensões físicas, sociais e culturais da urbanização no sul-global e, em particular, nos espaços africanos a sul do Sahara.

Percurso que o autor foi desbravando não só apoiado no acervo bibliográfico mais recente a que fiz referência, mas também na experiência pessoal, decorrente dos contatos no terreno e da participação em conferências e reuniões de trabalho, de que nos vai dando conta.

Trata-se de facto de uma investigação em curso, um trabalho em progresso que importa acompanhar atentamente. Trata-se, por outro lado, de um documento pedagógico de muito interesse para a multiplicidade de estudantes e estudiosos do fenómeno urbano do "Sul Global", bem como para os que têm a difícil, mas estimulante, missão de acompanhar e reencaminhar os processo complexos que configuram uma das maiores revoluções da história da humanidade.

\section{O PEDAGOGO E O MESTRE}

Uma das marcas mais notáveis em Ilídio do Amaral enquanto professor é o profundo respeito pelos alunos, revelado nas múltiplas dimensões do que deve ser a relação entre o professor e os alunos: desde logo, algo que se vai esquecendo, mas que está no cerne da atividade docente: a preparação das aulas, depois, o ouvir atentamente, a disponibilidade, a paciência... o cumprimento rigoroso dos horários das aulas, da entrega em tempo convencionado dos trabalhos de avaliação...enfim, o respeito pelos alunos.

Recordo com frequência a minha primeira aula de Geografia, na Faculdade de Letras: Geografia Física I. O então $2^{\circ}$ Assistente, comportava-se já como um verdadeiro mestre - do vestir ao falar, clareza na exposição, atento às dúvidas dos alunos, mostrando um entusiasmo sereno que com o tempo nos contagiava eficazmente.

Ao longo dos 5 anos da licenciatura, Ilídio do Amaral esteve sempre presente, nas visitas de estudo e nas excursões anuais do curso que organizava com rigor, nos colóquios quinzenais de que na maior parte dos casos se encarregava da curadoria e se necessário da animação.

Assim como recordei a primeira aula, recordo a ajuda e o apoio na minha dissertação de doutoramento, orientada por Orlando Ribeiro, o que me permitiu fazer muitas melhorias, pela discussão e pelo contraditório proporcionados: ele não concordava com muitos dos pressupostos teóricos em que eu me baseava; mas Ilídio do Amaral fez uma leitura rigorosíssima da primeira versão do manuscrito, anexando capítulo a capítulo páginas e páginas, manuscritas, com dúvidas, sugestões, aditamentos.

Assumindo o risco de repetir algo do que já disse, mas às vezes é útil repetir, permitam-me que transcreva aqui uma passagem do agradecimento que fiz aos meus mestres, por altura da fantástica homenagem que amigos, alunos, colegas e companheiros de variadas lides me proporcionaram na Reitoria da Universidade de Lisboa em 28 de Novembro de 2007: Recordo a primeira aula do Curso de Geografia na Faculdade de Letras - na sala do fundo do Centro de Estudos Geográficos, não havia memória de tantos alunos no $1^{\circ}$ ano (uns 17, creio, mais que nos restantes 4 anos da Licenciatura!). O então $2^{\circ}$ Assistente, entrou com porte de Professor: elegante, de gravata, causou logo boa impressão e o tempo veio confirmá-lo: Ilídio do Amaral era o professor que melhor vestia, com simplicidade, elegância e no espírito do tempo. 
Deu-nos o programa, as regras do jogo e muitos conselhos, que me foram úteis ao longo do curso e, talvez o mais importante, ensinou-me a gostar da Geografia Física, primeiro a Geomorfologia e depois a Climatologia.

Ao longo do curso senti sempre o acompanhamento, o aconselhamento e o patrocínio recorrente de Ilídio do Amaral. Quando em Outubro de 1965, quatro meses após concluir a Licenciatura e um mês de estágio de campo no Douro, a pensar num doutoramento sobre o Douro e a Vinha e o Vinho, sou lançado aos bichos na ESBAL, para ensinar Geografia Física e Geografia Humana aos alunos do $4^{\circ}$ e $5^{\circ}$ anos de Arquitectura, o que me salvou foi a preciosa ajuda de Ilídio do Amaral: quer no desenho dos programas quer na bibliografia adequada a arquitectos. Começou aí a minha aprendizagem para o Planeamento Urbano e Regional.

Poucos anos passados após a minha estadia na Suécia, concluía a minha dissertação de doutoramento, sob a orientação de Orlando Ribeiro e a ajuda de muita gente, como de resto ficou referido nos agradecimentos. Ilídio do Amaral, além de dicas e dos incentivos, foi o leitor mais atento e mais criticamente eficaz do manuscrito. As suas correcções iam das gralhas e do estilo, directamente sobre o papel dactilografado, aos comentários, pertinentes e estimulantes, feitos numas folhinhas A5, norma no CEG de então.

Foi ainda Ilídio do Amaral que me acolheu, já depois de doutorado, na sua área de investigação dedicada às questões urbanas, onde pude, com toda a liberdade, dinamizar um pequeno grupo de jovens interessados em estudar Lisboa. Surgiu daí o embrião da futura Linha de Ação E.P.R.U. (Estudos para o Planeamento Regional e Urbano), que ainda perdura, se não já na designação do grupo de investigadores, pelo menos na série de publicações, de que acabei de receber o número 70 - Integração de Dados Estatísticos na Classificação de Imagens de Satélite, de Jorge Rocha e Paulo Morgado Sousa.

Ilídio do Amaral, que tem acompanhado a minha carreira académica desde o primeiro ano da Faculdade, ainda há dias me escrevia com muita amizade, a lembrar-me da necessidade de dar mais atenção à Academia das Ciências, agradeci o "lembrete/ralhete" e vou procurar mais uma vez, seguir os seus sempre oportunos e úteis conselhos". Fim de citação.

\section{UM TRABALHADOR INCANSÁVEL, UM DEDICADÍSSIMO SERVIDOR DA COISA PÚBLICA}

Ilídio do Amaral tem um registo impressionante de cargos de direção no âmbito da gestão universitária, tanto no setor público, como no setor privado. A essas funções a que nos referiremos de seguida juntam-se inúmeras participações em comissões e assessorias diversas a instituições públicas, no País e fora do País, merecendo referência especial a colaboração dada às jovens universidades de Angola e de Cabo Verde.

Assim, na Universidade de Lisboa, onde realizou todo o seu percurso, foi membro do Senado, Vice-Reitor e Reitor. Funções desempenhadas num período difícil, de transição para o regime democrático, onde a personalidade e o saber fazer de Ilídio do Amaral foram decisivos no bom sucesso dessa transição, com incremento da projeção internacional da Universidade de Lisboa.

No Instituto de Alta Cultura foi Vogal do Conselho Superior, Vice-Presidente e Presidente; na Junta de Investigação Científica do Ultramar foi Vogal do Conselho Superior e Vice-Presidente; foi membro dos conselhos científicos da JNICT (Junta Nacional de Investigação Científica e Tecnológica); foi ainda membro do Conselho Superior de Ciência e Tecnologia.

Ainda no âmbito da gestão e políticas do ensino superior e da investigação científica destaca-se a participação em comissões da OCDE e na Comissão do Ensino Superior do Conselho da Europa.

Assinale-se ainda a colaboração com a Fundação Calouste Gulbenkian e com a UNESCO, sob cuja égide elaborou a proposta de reestruturação do setor das Ciências Sociais e Humanas da Universidade Agostinho Neto. 
O saber adquirido na gestão do ensino superior público foi posto ao serviço da valorização do ensino superior privado, quer enquanto Reitor da Universidade Internacional, quer como Presidente do Instituto Politécnico Internacional. Entre múltiplas tarefas e iniciativas levadas a cabo neste âmbito, relevam-se os esforços desenvolvidos no sentido da institucionalização do Conselho de Reitores das Universidades Privadas.

Decerto que na perspetiva de um geógrafo, antigo aluno e discípulo, a atividade de Ilídio do Amaral no âmbito das instituições de ensino e investigação das ciências geográficas merecem particular relevo. De todas, destacarei o Centro de Estudos Geográficos, fundado por Orlando Ribeiro há mais de 60 anos, e que deve a Ilídio do Amaral a continuidade, consolidação e projeção nacional e internacional. Enquanto Secretário do CEG, Ilídio do Amaral além de apoiar e ajudar Orlando Ribeiro, dirigiu importantes projetos de investigação que nos anos 1960 e 1970 contribuíram para a afirmação não só do CEG, como da Geografia Portuguesa. No mesmo período, e a partir do CEG, Ilídio do Amaral sucede a Orlando Ribeiro na Presidência da Comissão Nacional de Geografia, membro da União Geográfica Internacional, representando assim a Geografia Portuguesa em congressos e conferências internacionais das Ciências Geográficas.

Quando nos anos 1970 começa a ocupar importantes cargos de gestão científica e universitária, muitos foram os que temeram que se ia perder um professor e um investigador, de que a Universidade tanto carecia. Mas tal não aconteceu; ainda em 1976, na cerimónia da tomada de posse como Reitor da Universidade de Lisboa, conferida pelo Decano da Universidade, o Professor Orlando Ribeiro, este afirmou ao concluir o seu discurso: "Nada mais acrescentarei senão o desejo de que o meu colega Ilídio do Amaral, cuja energia conheço e aprecio, se aplique com êxito às novas tarefas que lhe incumbem, e encontre tempo para continuar a servir a Geografia, que tão fortemente vincou a sua personalidade e a sua vocação". - Como o tempo acabaria por demonstrar, passados quase 40 anos, podemos verificar que Ilídio do Amaral correspondeu plenamente aos votos do velho Mestre: também serviu a Geografia, exercitando a sua vocação de forma superlativa.

\section{A OBRA PUBLICADA}

Como procurei mostrar, o percurso de uma vida académica é muito mais do que um registo bibliográfico, mas no cômputo final a obra publicada merece um registo individualizado, já que no essencial é o que mais se projeta no tempo e no espaço.

Ao longo de 58 anos de atividade científica, o tempo que medeia entre a apresentação da sua dissertação de licenciatura, São Paulo de Assunção de Luanda, Lisboa, 1956, e a atualidade, Ilídio do Amaral apresenta 480 títulos na sua extensa e diversificada bibliografia.

Desde logo, evidenciou dois interesses principais nos temas de investigação: a Geografia Urbana e a Geomorfologia. Progressivamente, outros temas foram ganhando peso na sua obra: Geografia Política, Geografia Histórica, História, Políticas de ensino universitário e Políticas de investigação científica.

Ainda nos anos 1950, na sequência da Dissertação de Licenciatura, publica alguns artigos sobre Luanda e na década seguinte, um importante estudo sobre a rede urbana de Angola (Amaral, 1962), trabalho original no contexto da Geografia Portuguesa, que colocou a chamada "Escola de Lisboa" no topo das investigações em Geografia Urbana. Entretanto, conhecem-se também os primeiros resultados dos estudos de Geomorfologia que com Orlando Ribeiro e Mariano Feio, vinha desenvolvendo no Norte de Angola e que foi obrigado a interromper devido à eclosão da Guerra Colonial (Ribeiro, Feio, Amaral, 1961).

Voltou então o fulcro das suas investigações para Cabo Verde, Ilha de Santiago, que, como vimos, seria o tema da sua dissertação de doutoramento (Amaral, 1964) - obra que mereceu o prémio Abílio Lopes do Rego da Academia das Ciências de Lisboa. 
O estudo da Geomorfologia continua como um dos eixos da atividade científica, destacando-se o artigo "Tendências da Geomorfologia" (Amaral, 1967), sendo ainda de referir a notícia na Revista Finisterra sobre "As inundações de 25/26 de Novembro de 1967" (Amaral, 1968a), mas o maior peso do seu trabalho na segunda metade dos anos 1960 foi canalizado para o já referido estudo sobre Luanda (Amaral, 1968b), e, logo no ano seguinte, publica uma síntese dos seus trabalhos sobre a segunda cidade de Moçambique "Beira, Cidade e Porto do Índico" (Amaral, 1969).

Em 1973 publica dois artigos de referência sobre a Geomorfologia de Angola "Contribuições para o conhecimento do Karst ou carso de Nova Caipemba, no noroeste de Angola" (Amaral, 1973a) e "Formas de «Inselberge» (ou montes-ilha) e de meteorização superficial e profunda em rochas graníticas do deserto de Moçamedes (Angola) na margem direita do rio Curoca" (Amaral, 1973b), temas a que voltaria num artigo publicado na revista Garcia da Horta, em 1977 "Paisagens Morfológicas do Deserto de Moçâmedes (Angola) entre os rios Cuoca e Cunene (1 a parte)” (Amaral, 1977).

Logo no ano seguinte publica na Finisterra um importante artigo sobre o fenómeno da urbanização em Angola (Amaral, 1978), tema que retoma numa conferência no Centro Cultural Português da Fundação Calouste Gulbenkian (Amaral, 1979a). Entretanto publica dois relatórios de referência sobre A Escola Geográfica de Lisboa e a sua contribuição para o conhecimento geográfico das Regiões Tropicais (Amaral, 1979b) e Formas e processos eólicos, com exemplos do Deserto de Moçâmedes (Amaral, 1979c).

No ano seguinte publica na revista Garcia da Orta o seu primeiro trabalho de referência no âmbito da Geografia Política "Entre o Cunene e o Cubango ou a propósito de uma fronteira africana" (Amaral, 1980-1981) e inicia a publicação da Bibliografia Geral de Cabo Verde (anotada e ilustrada) (Amaral, 1980; 1981a).

É por esta altura que começa a elaborar e a publicar estudos sobre a gestão universitária e gestão da investigação científica em Portugal (Amaral, 1981b; Amaral, 1981c).

Em 1983 é publicada a sua primeira Memória da Academia das Ciências de Lisboa, sobre "A cidade e o futuro: a propósito da explosão urbana mundial" (Amaral, 1983a). Neste mesmo ano relevam-se ainda dois trabalhos de síntese sobre a produção dos geógrafos da "Escola Geográfica de Lisboa", um na Garcia da Orta (Amaral, 1983b) e outro na Revista da Faculdade de Letras (Amaral, 1983c) e o primeiro estudo sobre os muceques de Luanda, na Finisterra (Amaral, 1983d).

Mantendo a Geomorfologia no centro das suas atividades científicas, como o demonstra o artigo sobre as paisagens com Inselberge nas regiões tropicais (Amaral, 1984a), é neste ano que Ilídio do Amaral revela uma forte propensão para os estudos de História, patente no ensaio sobre Luanda em meados do século XIX, a partir de um texto de 1848, publicado na Garcia da Orta (Amaral, 1984b) e no estudo sobre a viagem de dois pombeiros angolanos através de Angola e Moçambique, no início do século XIX, também este publicado na Garcia da Orta (Amaral e Amaral, 1984a). Ainda neste ano, os mesmos autores apresentaram uma exaustiva bibliografia científica de Orlando Ribeiro (Amaral e Amaral, 1984b).

No ano seguinte, Ilídio do Amaral mantém um ritmo de publicação notável, repartido pelas suas áreas de investigação prediletas - as cidades do Terceiro Mundo (Amaral, 1985b) e da África Tropical em particular (Amaral, 1985a); a Geografia Política, através de mais uma memória da Academia das Ciências de Lisboa, sobre Fronteiras, Estado e Nação em Áfricas (Amaral, 1985c) e a geomorfologia do Sul de Angola - "Processos e formas de evolução do relevo em rochas da orla sedimentar do deserto de Moçâmedes" (Amaral, 1985d). Publica ainda uma comunicação feita à Academia da Marinha, sobre a Missão Landsat (Amaral, 1985e) e mais dois trabalhos, também com Ana Amaral - o início de uma coletânea de textos comentados sobre as regiões tropicais (Amaral e Amaral, 1985a) e um texto sobre a Utopia de Tomas Morus (Amaral e Amaral, 1985b). 
O ano de 1986 continua a demonstrar uma diversificação de interesses: a geografia política, "Fronteiras do Sahel: alguns aspectos geográficos" (Amaral, 1986a) e "The geographical factor in the formation of modern states" (Amaral, 1986b); geografia histórica, "Participação portuguesa para o conhecimento do continente africano no século actual" (Amaral, 1986c) e "Progressos do conhecimento geográfico da África em finais do século XIX” (Amaral, 1986d); sem se afastar nunca da sua geomorfologia - "Em redor do tema da flexura marginal, ou litoral, dos continentes" (Amaral, 1986e).

No ano seguinte os mais significativos trabalhos publicados são de novo de Geografia Política "A irrupção de estados-insulares após a segunda guerra mundial: um facto novo na geografia política" (Amaral, 1987a) e de Geografia Histórica com "Mbanza Kongo, cidade do Congo ou São Salvador. Contribuição para o conhecimento geográfico de uma aglomeração urbana ao sul do Equador, nos séculos XVI e XVII" (Amaral, 1987b).

Em 1988, tendo continuado a publicar nos domínios da sua predileção, destaca-se um ensaio, resultante de uma comunicação à Academia das Ciências, "Lisboa uma capital do Renascimento", publicada em "O Humanismo Português 1500-1600" (Amaral, 1988). No final da década oferece-nos, entre outros, trabalhos de reflexão sobre o espaço da Península Ibérica (Amaral, 1989) e sobre a geografia tropical de Gilberto Freyre (Amaral, 1990).

Ao longo dos anos 1990 verifica-se algum abrandamento no ritmo das publicações o que se liga decerto à maior intensidade na gestão universitária e científica, nacional e internacional, mas que logo é recuperado no final do século. Permaneceram os temas, com um crescente enfoque em África e no Atlântico, destacando-se alguns trabalhos, inclusive os premiados, a que já nos referimos. Na História, releva-se o estudo sobre a organização de novos territórios no Atlântico Sul do século XVI (Amaral, 1991), as notas de Geografia Histórica sobre a cidade de Mbanza Congo (Amaral, 1992), o estudo sobre o Reino do Congo nos séculos XV e XVI, premiado pela Academia Portuguesa de História (Amaral, 1996a), o ensaio sobre Luanda durante "o consulado" de Paulo Dias de Novais (Amaral, 2000a); na Geografia Política, tem uma nota introdutória no Livro Global boundaries. World boundaries (Amaral, 1994), um artigo sobre fronteiras internacionais africanas (Amaral, 1997a); na Geomorfologia, publicou um artigo de síntese sobre as regiões tropicais (Amaral, 2000b); na Geografia Urbana, destaca-se uma bibliografia selecionada de estudos de Geografia Urbana (Amaral, 1997b), um ensaio sobre as cidades insulares atlânticas no século XVI (Amaral, 1999a) e uma bibliografia de Luanda (Amaral, 1999b); anota-se ainda uma nova incursão na reflexão sobre a obra de Gilberto Freire (Amaral, 1996b) e nas questões da tropicalidade (Amaral, 1998), bem como um estudo sobre os nacionalismos africanos, "memórias e reflexões em homenagem ao Mário Pinto de Andrade, 1928-1990" (Amaral, 2000c).

E Ilídio do Amaral entra no século XXI com um impressionante desempenho na investigação científica e correlativas publicações; não se afastando significativamente da rota anterior, manteve uma maior propensão para as abordagens históricas, procurando sempre novas temáticas, no espírito do tempo. É assim que em 2003 publica na Africana Studia o artigo "Presença da mulher africana ao sul do Sara na Cultura e na Ciência: questões de Género" (Amaral, 2003a). De resto mantém-se fiel à Geografia Urbana (Amaral, 2001a, 2002a, 2002b, 2005a, 2005b, 2007a, 2012d e 2013b), assim como à Geografia Física com natural ênfase na Geomorfologia, tendo introduzido a problemática dos riscos, numa interessante abordagem ao sítio de Luanda (Amaral, 2001c, 2002b,2006).

No domínio da História, salientamos o estudo sobre o papel das ilhas atlânticas na rede de globalização dos séculos XV a XVII (Amaral, 2001b), outro sobre a importância das "fontes cruzadas" para a História de Angola (Amaral, 2002c), ainda as relações entre História e Geografia, na História de Angola (Amaral, 2007b), a colonização europeia da África Subsariana (Amaral, 2008c) e "Reflexões de um geógrafo em torno do tema Memória e História. A construção das identidades” (Amaral, 2010). 
A Geografia Política continuou também no conjunto dos temas tratados, com novas abordagens, como a dos desafios que se colocam aos países lusófonos face à globalização (Amaral, 2002d; Amaral, 2005c).

Uma nova preocupação respeita os estudos culturais nas suas várias vertentes, reconhecendo-se uma clara orientação para os territórios africanos, como "Cabo Verde - permanência e rupturas" (Amaral, 2001d), "Acerca da Paisagem" (Amaral, 2001e), e o ensaio "Sobre culturas e intercâmbios culturais" (Amaral, 2009c).

Mas à medida que avança o século XXI o maior peso do labor de Ilídio do Amaral recai sobre temas da história e do património da Academia das Ciências de Lisboa, como já referimos anteriormente.

Ainda assim, ficaram sem referência muitas das publicações de Ilídio do Amaral, por um lado, por manifesta falta de espaço nesta função, por outro, pela dificuldade de chegar a um bom ordenamento que, fazemos votos, o autor venha a leva a cabo, oferecendo-nos uma série de opúsculos, que a sua obra bem merece e os seus leitores há muito aguardam.

\section{UM CONSTRUTOR DE PONTES, UM PROMOTOR DE DIÁLOGOS - ASSIM, COMO QUEM NÃO QUER A COISA}

É reconhecida a capacidade que Ilídio do Amaral tem demonstrado possuir na abordagem de temas de vários domínios científicos, mormente nos que se situam no vasto conjunto das Humanidades e Ciências Sociais, sem deixar de inscrever a sua matriz de geógrafo, estabelecida na regra do seu mestre Orlando Ribeiro, na interseção com as Ciências da Natureza.

A História de África, e em particular de Angola, têm vindo a merecer uma atenção muito especial e algumas das suas obras afirmaram-se como essenciais para o conhecimento da História de África. Um dos mais notáveis estudos que produziu neste âmbito foi O Reino do Congo, os Mbundu (ou Ambundos), o reino dos "Ngola" (ou de Angola) e a presença Portuguesa de finais do século XV a meados do século XVI, (Lisboa, 1996), que obteve o Prémio História Calouste Gulbenkian - Presença de Portugal no Mundo, da Academia Portuguesa de História.

É já vasta e diversificada a bibliografia histórica de Ilídio do Amaral de que podemos apontar como exemplos o estudo sobre Paulo Dias de Novais: O Consulado de Paulo Dias de Novais. Angola no último quartel do século XVI e primeiro do século XVII (Amaral, 2000a), ou Importância das «fontes cruzadas» na historiografia angolana (Reflexões de um geógrafo) (Amaral, 2000d).

Ainda nas Ciências Sociais e tomando como referência trabalhos dos últimos 15 anos, salientamos no domínio da Ciência Política o ensaio Em torno dos nacionalismos africanos. Memórias e reflexões em homenagem ao Mário Pinto de Andrade, 1928-1990. (Amaral, 2000c).

Ainda nas Ciências Sociais sublinham-se as aproximações à Economia e Finanças, em estudos como "Importância do sector informal da economia urbana em países da África Subsariana" (2005a) e "Operações financeiras no sector informal das cidades da África Subsariana” (2007a).

Mas as pontes e os diálogos têm sido recorrentes também no âmbito das ciências físicas e naturais, bem como nas articulações com o ordenamento do território e urbanismo. Nestes domínios a produção recente tem sido notável, como nestes dois exemplos: "Luanda e o seus dois arcos complexos de vulnerabilidade e risco: o das restingas e o das escarpas abarrocadas" (2002); "O rio Cambongo-Neguza e os seus afluentes: um exemplo da complexidade de padrões de drenagem em Angola” (2006).

Nas ciências como nas artes, as verdadeiras obras de um autor acabam por definir um percurso de vida, uma narrativa da pessoa, uma autobiografia.

Esta dimensão está bem patente no percurso científico e académico de Ilídio do Amaral, tal como o podemos aperceber, a par e passo. 


\section{REFERÊNCIAS BIBLIOGRÁFICAS}

Amaral, I. (1956). São Paulo de Assunção de Luanda. (Dissertação de licenciatura em Geografia). Lisboa: Faculdade de Letras da Universidade de Lisboa.

Amaral, I. (1957). Aspectos económicos da cidade de Luanda [Economic aspects of the city of Luanda]. Boletim do Instituto de Angola, 9, 51-60.

Amaral, I. (1959). Subsídios para o estudo da evolução da população de Luanda [Subsidies for the study of the evolution of the population of Luanda]. Garcia de Orta, 7(2), 212-226.

Amaral, I. (1961). Descrição de Luanda setecentista vista através de uma planta de 1755 [Description of 17 th century Luanda seen through an urban plan of 1755]. Garcia de Orta, 9(3), 409-420.

Amaral, I. (1962). Ensaio de um estudo geográfico da rede urbana de Angola [Essay on a geographic study of the urban network of Angola]. Col. Estudos, Ensaios e Documentos, Vol. 97. Lisboa: Junta de Investigações do Ultramar.

Amaral, I. (1964). Santiago de Cabo Verde: a Terra e os Homens [Santiago de Cabo Verde: the Earth and Man]. Col. Memórias, Vol. 48, (Prémio Abílio Lopes do Rego, da Academia das Ciências de Lisboa). Lisboa: Junta de Investigações do Ultramar.

Amaral, I. (1966). Johannesburg. Do campo mineiro à conurbação [Johannesburg. From the mine field to the conurbation]. Finisterra - Revista Portuguesa de Geografia, I(2), 240-256.

Amaral, I. (1967). Tendências da Geomorfologia [Trends in Geomorphology]. Finisterra - Revista Portuguesa de Geografia, II(3), 17-38.

Amaral, I. (1968a). As inundações de 25/26 de Novembro de 1967 na região de Lisboa [The floods of 25/26 November 1967 in the Lisbon region]. Finisterra - Revista Portuguesa de Geografia, III(5), 79-84.

Amaral, I. (1968b). Luanda. Estudo de geografia urbana [Luanda. A study of urban geography]. Col. Memórias, Vol. 53, (Prémios Almirante Gago Coutinho, da Sociedade de Geografia de Lisboa, e da Câmara Municipal de Luanda). Lisboa: Junta de Investigações do Ultramar

Amaral, I. (1969). Beira, cidade e porto do Índico [Beira, city and port of the Indian Ocean]. Finisterra Revista Portuguesa de Geografia, IV(7), 76-93.
Amaral, I. (1973a). Contribuição para o conhecimento do Karst ou carso de Nova Caipemba, no noroeste de Angola [Contribution to the knowledge of the Karst of Nova Caipemba in north-western Angola]. Garcia de Orta, Série de Geografia, 1(2), 1-28.

Amaral, I. (1973b). Formas de «Inselberge» (ou montes-ilhas) e de meteorização superficial e profunda em rochas graníticas do deserto de Moçâmedes (Angola), na margem direita do rio Curoca [Forms of "Inselberg" deep and superficial weathering on granite rocks of the Moçâmedes desert (Angola), on the right bank of the Curoca river]. Garcia de Orta, Série de Geografia, 1(1), 1-34.

Amaral, I. (1977). Paisagens morfológicas do deserto de Moçâmedes (Angola) entre os rios Curoca e Cunene ( $1^{\mathrm{a}}$. parte) [Morphological landscapes of the Moçâmedes (Angola) desert between the Curoca and Cunene rivers (1st part)]. Garcia de Orta, Série de Geografia, 4(1-2), 1-28.

Amaral, I. (1978). Contribuição para o conhecimento do fenómeno de urbanização em Angola [Contribution to the knowledge of the phenomenon of urbanization in Angola]. Finisterra - Revista Portuguesa de Geografia, XIII(25), 43-76.

Amaral, I. (1979a). Vers la compréhension de la géographie urbaine de l'Angola [Towards an understanding of the urban geography of Angola]. Arquivos do Centro Cultural Português. Paris: Fundação Calouste Gulbenkian.

Amaral, I. (1979b). A "Escola geográfica de Lisboa" e a sua contribuição para o conhecimento geográfico das Regiões Tropicais [The "Geographical School of Lisbon" and its contribution to geographical knowledge of the Tropical Regions]. Relatório da Linha de Acção no 5 - Estudos de Geografia das Regiões Tropicais, 1. Lisboa: Centro de Estudos Geográficos, 87 p. (policop.)

Amaral, I. (1979c). Formas e processos eólicos, com exemplos do deserto de Moçâmedes [Wind forms and processes, with examples from the Moçâmedes desert]. Relatório da Linha de Acção no 5 Estudos de Geografia das Regiões Tropicais, 4. Lisboa: Centro de Estudos Geográficos, 76 p., il. +31 folhas de estampas. (policop.).

Amaral, I. (1980-81). Entre o Cunene e o Cubango, ou a propósito de uma fronteira africana [Between 
Cunene and Cubango, or the purpose of an African border]. Garcia de Orta, Série de Geografia, 6(1-2), 1-50.

Amaral, I. (1980). Bibliografia geral de Cabo Verde. (Anotada e ilustrada) [General bibliography of Cape Verde. (Annotated and illustrated)]. IV, Relatório da Linha de Acção no 5 - Estudos de Geografia das Regiões Tropicais, 6, 154 p. (policop.). Lisboa: Centro de Estudos Geográficos

Amaral, I. (1981a). Bibliografia científica de Orlando Ribeiro [Scientific bibliography of Orlando Ribeiro]. Lisboa: Centro de Estudos Geográficos, 99 p. (policop.)

Amaral, I. (1981b). Algumas reflexões em torno de um projecto de decreto-lei sobre a autonomia das universidades portuguesas [Some reflections on a draft decree-law on the autonomy of Portuguese universities]. Lisboa, 17 p. + quadros e estatísticas. (policop.).

Amaral, I. (1981c). Duas notas em torno de alguns problemas sobre a gestão da investigação científica universitária em Portugal [Two notes about some problems on the management of academic scientific research in Portugal]. Lisboa, 15 p. (policop.).

Amaral, I. (1981d). Homenagem a Orlando Ribeiro [Homage to Orlando Ribeiro]. Finisterra - Revista Portuguesa de Geografia, XVI(31), 5-14.

Amaral, I. (1982). Paisagens morfológicas do deserto de Moçâmedes (Angola), entre os rios Curoca e Cunene (2a. parte) [Morphological landscapes of the Moçâmedes desert (Angola), between the Curoca and Cunene rivers (2nd part)]. Garcia de Orta, Série de Geografia, 7(1-2), 1-34.

Amaral, I. (1983a). A cidade e o futuro: a propósito da explosão urbana mundial [The city and the future: about the global urban explosion]. In Imprensa Nacional Casa da Moeda (Ed.), Memórias da Academia das Ciências de Lisboa [Memories of the Lisbon Academy of Sciences] (pp. 147-158), vol.23. Lisboa: Classe de Letras.

Amaral, I. (1983b). Estudos de geografia das regiões tropicais (contribuição da Escola Geográfica de Lisboa) [Geographic studies of the tropical regions (contribution of the Geographical School of Lisbon)]. Garcia de Orta, Série de Geografia, 8(1-2), 1-44.

Amaral, I. (1983c). Geógrafos e Geografia na Faculdade de Letras de Lisboa [Geographers and Geography at the Faculty of Leters of Lisbon]. Revista da Faculdade de Letras, 68-82.
Amaral, I. (1983d). Luanda e os seus "muceques", problemas de Geografia Urbana [Luanda and its "muceques", problems of Urban Geography]. Finisterra - Revista Portuguesa de Geografia, XVIII(36), 293-325.

Amaral, I. (1984a). Acerca das paisagens com inselberge (ou montes-ilhas) em regiões tropicais [About landscapes with inselbergs (or monadnocks) in tropical regions]. In Centro de Estudos Geográfi$\cos$ (Ed.), Livro de Homenagem a Orlando Ribeiro [Homage to Orlando Ribeiro] (pp. 367-375), Vol. 1. Lisboa: Centro de Estudos Geográficos, Instituto Nacional de Investigação Científica.

Amaral, I. (1984b). Luanda em meados do século XIX, revelada num texto de 1848 [Luanda in the mid-nineteenth century, revealed in a text from 1848]. Garcia de Orta, Série de Geografia, 9(1-2), 1-16.

Amaral, I. (1984c). Homenagem a Orlando Ribeiro [Homenage to Orlando Ribeiro]. In Centro de Estudos Geográficos (Ed.), Livro de Homenagem a Orlando Ribeiro [Homage to Orlando Ribeiro] (pp. 19-26), Vol. 1. Lisboa: Centro de Estudos Geográficos, Instituto Nacional de Investigação Científica.

Amaral, I. (1985a). Acerca das cidades da África tropical: notas bibliográficas [On cities in tropical Africa: bibliographical notes]. Revista Internacional de Estudos Africanos, 3, 225-230.

Amaral, I. (1985b). Notas bibliográficas sobre as cidades do Terceiro Mundo (I) [Bibliographical notes on Third World cities (I)]. Finisterra - Revista Portuguesa de Geografia, XX(39), 163-172.

Amaral, I. (1985c). Fronteiras, Estado e Nação em África. Apontamentos de geografia política [Frontiers, State and Nation in Africa. Notes on political geography]. In Imprensa Nacional da Casa da Moeda (Ed.), Memórias da Academia das Ciências de Lisboa (pp. 43-68). Lisboa: Classe de Letras.

Amaral, I. (1985d). Processos e formas de evolução do relevo em rochas da orla sedimentar do deserto de Moçâmedes (Angola) [Processes and forms of evolution of rock relief in the sedimentary margin of the Moçâmedes desert (Angola)]. Garcia de Orta, Série de Geografia, 10(1-2), 1-40.

Amaral, I. (1985e). A redescoberta do Mundo na segunda metade do século XX. Missão Landsat [The rediscovery of the World in the second half of the 20th century. Landsat Mission]. Lisboa: Academia de Marinha. 
Amaral, I. (1986a). Fronteiras do Sahel: alguns aspectos geográficos [Borders of the Sahel: some geographical aspects]. Garcia de Orta, Série de Geografia, 11(1-2), 1-54.

Amaral, I. (1986b). The geographical factor in the formation of modernstates. Finisterra - Revista Portuguesa de Geografia, XXI(41), 57-76.

Amaral, I. (1986c). Participação portuguesa para o conhecimento do continente africano no século actual [Portuguese participation in knowledge creation on the African continent in the current century]. Boletim da Sociedade de Geografia de Lisboa, 104(7-12), 123-143.

Amaral, I. (1986d). Progressos do conhecimento geográfico da África em finais do século XIX [Progress in geographical knowledge of Africa in the late nineteenth century]. In Academia das Ciências de Lisboa (Ed.), História e desenvolvimento da Ciência em Portugal [History and development of science in Portugal] (pp. 1141-1171), Vol. 2. Lisboa: Academia das Ciências de Lisboa.

Amaral, I. (1986e). Em redor do tema da flexura marginal, ou litoral, dos continentes [Around the theme of the marginal, or coastal, flexure of the continents]. In Brito, R. (Coord.), Estudos em Homenagem a Mariano Feio [Studies in Homage to Mariano Feio] (pp. 3-15). Lisboa: Public. Patrocinada por Instituto Nacional de Investigação Científica, Instituto de Investigação Científica Tropical, Fundação Calouste Gulbenkian e Faculdade de Ciências Sociais e Humanas da Universidade Nova de Lisboa.

Amaral, I. (1987a). A irrupção de estados-insulares após a segunda guerra mundial: um facto novo em geografia política [The eruption of island states after the Second World War: a new fact in political geography]. Finisterra - Revista Portuguesa de Geografia, XXII(44), 297-359.

Amaral, I. (1987b). Mbanza Kongo, cidade o Congo ou São Salvador. Contribuição para o conhecimento geográfico de uma aglomeração urbana africana ao sul do equador, nos séculos XVI e XVII [Mbanza Kongo, Congo or San Salvador city. Contribution to geographic knowledge of an African urban agglomeration south of the equator in the 16th and 17th centuries]. Garcia de Orta, Série de Geografia, 12(1-2), 1-40.

Amaral, I. (1988). Lisboa uma capital do Renascimento [Lisbon a Renaissance capital]. In Academia das
Ciências de Lisboa (Ed.), O Humanismo português 1500-1600 [Portuguese Humanism 1500-1600] (pp. 619-652). Lisboa: Academia das Ciências de Lisboa.

Amaral, I. (1989). El espacio geografico de la Península Ibérica [The geographic space of the Iberian Peninsula]. In E. Barba (Coord.), Iberoamérica, una comunidad (pp.51-67), vol. 1. Madrid: Ediciones de Cultura Hispánica.

Amaral, I. (1990). A geografia tropical de Gilberto Freyre [The tropical geography of Gilberto Freyre]. In Universidade Internacional (Ed.), Leituras do Tempo. História, Filosofia, Biologia, Literatura, Política e Economia do Tempo [Readings of Time. History, Philosophy, Biology, Literature, Politics and Economy of Time] (pp. 299-315). Lisboa: Universidade Internacional.

Amaral, I. (1991). Medidas portuguesas para a organização dos novos territórios nas margens continentais do Atlântico sul no século XVI [Portuguese measures for the organization of new territories on the continental shores of the South Atlantic in the 16th century]. Revista da Universidade de Coimbra, 36, 277-316.

Amaral, I. (1992). Notas de geografia histórica sobre uma capital africana do século XVI: Mbanza Kongo, no Reino do Congo [Historical geography notes on a 16th century African capital: Mbanza Kongo in the Kingdom of Congo]. In J. Serrão (Coord.), Estudos de Homenagem a Jorge Borges de Macedo [Studies of Homage to Jorge Borges de Macedo] (pp. 291-310). Lisboa: Instituto Nacional de Investigação Científica, Centro de Arqueologia e História da Universidade de Lisboa.

Amaral, I. (1994). New reflexions on the theme of international boundaries. In H. Clive (Ed.), Global boundaries. World boundaries (pp. 16-23), vol. 1. Londres, Nova Iorque: Routledge.

Amaral, I. (1996a). O reino do Congo, os mbundu (ou ambundos), o reino dos "ngola" (ou de Angola) e a presença portuguesa, de finais do século XV a meados do século XVI [The kingdom of the Congo, the mbundu (or ambundos), the kingdom of the "ngola" (or Angola) and the Portuguese presence, from the late 15 th century to the 16 th century]. (Prémio de História Calouste Gulbenkian, Presença de Portugal no Mundo, 1997, da Academia Portuguesa da História). Lisboa: Instituto de Investigação Científica Tropical. 
Amaral, I. (1996b). O homem e a sociedade em regiões tropicais: o caso brasileiro, segundo Gilberto Freyre [Mankind and society in tropical regions: the Brazilian case, according to Gilberto Freyre]. Garcia de Orta, Série de Geografia, 15(1), 1-12.

Amaral, I. (1997a). Fronteiras internacionais africanas [African international borders]. In Comissão Nacional para as Comemorações dos Descobrimentos Portugueses (Ed.), As Fronteiras de África [The Borders of Africa] (pp. 13-22). Lisboa: Comissão Nacional para as Comemorações dos Descobrimentos Portugueses.

Amaral, I. (1997b). Bibliografia seleccionada: estudos de geografia urbana [Selected bibliography: studies in urban geography]. Lisboa: Edição do autor.

Amaral, I. (1997c). Homenagem ao Professor Orlando Ribeiro [Homage to Professor Orlando Ribeiro]. In Instituto de Investigação Científica Tropical (Ed.), A erupção vulcânica de 1995 na ilha do Fogo (Cabo Verde) [The 1995 volcanic eruption on Fogo Island (Cape Verde)] (pp. 235-256). Lisboa: Instituto de Investigação Científica Tropical.

Amaral, I. (1998). Vicissitudes geográfico-políticas na Zona Tropical [Geo-political vicissitudes in the Tropical Zone]. In L. C. Cunha, \& S. Vilanova (Org.), Os Trópicos na era da Globalização [The Tropics in the Era of Globalization] (pp. 35-63). Recife: Fundação Joaquim Nabuco.

Amaral, I. (1999a). Do "solitário ermo» à «afamada cidade»: reflexões sobre as cidades insulares atlânticas no século XVI" [From "lonely wilderness' to 'famous city': reflections on Atlantic island cities in the 16th century]. Ponta Delgada: Colóquio Comemorativo dos 450 anos da cidade de Ponta Delgada: Actas, Universidade dos Açores e Câmara Municipal de Ponta Delgada, pp. 33-47.

Amaral, I. (1999b). Luanda: referências bibliográficas [Luanda: bibliographical references]. Lisboa: Centro de Geografia do Instituto de Investigação Científica Tropical, 57 p. (policop.).

Amaral, I. (2000a). O consulado de Paulo Dias de Novais. Angola no último quartel do século XVI e primeiro do século XVII [The consulate of Paulo Dias de Novais. Angola in the last quarter of the 16th century and the first quarter of the 17th century]. Lisboa: Instituto de Investigação Científica Tropical, 280 p., il.
Amaral, I. (2000b). Geografia física das regiões tropicais: reflexões geomorfológicas (I) [Physical geography of tropical regions: geomorphological reflections (I)]. Garcia de Orta, Série de Geografia, 17(1-2), 1-22.

Amaral, I. (2000c). Em torno dos nacionalismos africanos. Memórias e reflexões em homenagem ao Mário Pinto de Andrade, 1928-1990) [On African nationalisms. Memories and reflections in homage to Mário Pinto de Andrade, (1928-1990)]. Porto: Granito, Editores e Livreiros.

Amaral, I. (2000d). Importância das «fontes cruzadas» na historiografia angolana (Reflexões de um geógrafo) [Importance of "cross sources" in Angolan historiography (Reflections of a geographer)]. Lisboa: Actas do II Seminário Internacional de História de Angola. As fontes e a sua interpretação, Comissão Nacional para as Comemorações dos Descobrimentos Portugueses, pp. 63-160.

Amaral, I. (2001a). Análise das estruturas e funções urbanas na África Ocidental antes da presença europeia [Analysis of urban structures and functions in West Africa prior to European presence]. Lisboa: Actas do Colóquio Internacional Universo Urbanístico Português 1415-1822, Comissão Nacional para as Comemorações dos Descobrimentos Portugueses, pp. 183-196.

Amaral, I. (2001b). As ilhas atlânticas e índicas como pontos nodais da rede de globalização iniciada nos séculos XV a XVII" [The Atlantic and Indian Ocean islands as nodal points of the globalization network that began in the 15th and 17th centuries]. Portos, Escalas e Ilhéus no relacionamento entre o Ocidente e o Oriente, Actas do "Congresso Internacional Comemorativo do Regresso de Vasco da Gama a Portugal”, Lisboa, Comissão Nacional para as Comemorações dos Descobrimentos Portugueses e Universidade dos Açores, vol. I, pp. 115-138.

Amaral, I. (2001c). Referências bibliográficas de interesse geomorfológico sobre as formas de evolução de vertentes, estabilidade das mesmas, movimentos de materiais e fenómenos correlacionados [Bibliographical references of geomorphological interest on the evolutionary forms of slopes, their stability, material movements and correlated phenomena]. Lisboa: Centro de Geografia do Instituto de Investigação Científica Tropical, 77 p. (policop.). 
Amaral, I. (2001d). Cabo Verde: permanências e rupturas [Cape Verde: permanence and ruptures]. In Centro de Estudos Africano (Ed.), Africana (pp. 13-48), 6-Especial. Porto: Universidade Portucalense.

Amaral, I. (2001e). Acerca de 'paisagem': apontamentos para um debate [On 'landscape': notes for a debate]. Finisterra - Revista Portuguesa de Geografia, XXXVI(72), 75-81.

Amaral, I. (2002a). Contribuição para uma bibliografia geográfica de Luanda [Contribution to a geographical bibliography of Luanda]. Garcia de Orta, Série de Geografia, 18(1-2), 47-67.

Amaral, I. (2002b). Luanda e os seus dois arcos complexos de vulnerabilidade e risco: o das restingas e ilhas baixas e o das escarpas abarrocadas [Luanda and its two complex arches of vulnerability and risk: the salt-marshes and low-lying islands and crowded escarpments]. Territorium - Revista de Geografia Física Aplicada no Ordenamento do Território e Gestão de Riscos Naturais, Minerva, 9, 89-115.

Amaral, I. (2002c). Construindo a história de Angola: a importância da utilização de fontes. Reflexões de um geógrafo [Building the history of Angola: the importance of using sources. Reflections of a geographer]. Lisboa: Instituto de Investigação Científica Tropical.

Amaral, I. (2002d). A comunidade dos Países de Língua Portuguesa perante alguns desafios da integração regional e da globalização [The community of Portuguese-speaking countries facing challenges of regional integration and globalization]. Garcia de Orta, Série de Geografia, 18(1-2), 21-32.

Amaral, I. (2003a). Presença da mulher africana ao sul do Sara na cultura e na ciência: questões de género [The presence of African women in Southern Sahara in culture and science: gender issues]. Africana Studia, 6, 153-171.

Amaral, I. (2003b). As Academias das Ciências na contextura da globalização [The Academies of Sciences in the context of globalization]. Lisboa: Edição do Autor.

Amaral, I. (2005a). Importância do sector informal da economia urbana em países da África subsariana [The importance of the informal sector of the urban economy in sub-Saharan African countries]. Finisterra - Revista Portuguesa de Geografia Lisboa, $L(79)$, 53-72.
Amaral, I. (2005b). Apontamentos sobre Luanda: uma capital colonial imperfeita [Notes on Luanda: an Imperfect Colonial Capital]. Cadernos da Faculdade de Arquitectura da Universidade Técnica de Lisboa, (Cidades Africanas), 5, 48-55.

Amaral, I. (2005c). Os Países Africanos de Língua Oficial Portuguesa face aos Desafios do Século XXI [Portuguese-speaking African Countries in the face of 21st Century challenges]. In T. C. Silva, M. Araúdo, \& C. Cardoso (Orgs.), 'Lusofonia' em África. História, Democracia e Integração Africana [Lusophony in Africa. History, Democracy and African Integration] (pp. 3-30). Dakar: CODESRIA.

Amaral, I. (2006). O rio Cambongo-Negunza e os seus afluentes: um exemplo da complexidade de padrões de drenagem em Angola [The Cambongo-Negunza river and its tributaries: an example of the complexity of drainage patterns in Angola]. Finisterra - Revista Portuguesa de Geografia, Lisboa, XLI(82), 15-48.

Amaral, I. (2007a). Operações financeiras no sector informal das cidades da África Subsariana [Financial operations in the informal sector of Sub-Saharan African cities]. In A. Esteves (Ed.), Geophilia, o sentir e os sentidos da Geografia. Homenagem a Jorge Gaspar [Geophilia, the feel and senses of Geography. Homage to Jorge Gaspar] (pp. 413-432). Lisboa: Centro de Estudos Geográficos.

Amaral, I. (2007b). Sobre as relações entre a Geografia e a História. Reflexões de um geógrafo [On the relations between Geography and History. Reflections of a geographer]. Luanda: III Encontro Internacional sobre História de Angola.

Amaral, I. (2008a). As Academias de Ciências na contextura da Globalização [The Academies of Sciences in the context of Globalization]. Lisboa: Edição do Autor.

Amaral, I. (2008b). Orlando Ribeiro Humanista [Orlando Ribeiro the Humanist]. Finisterra Revista Portuguesa de Geografia, XLIII(85), 45-56.

Amaral, I. (2008c). Reflexões em torno da Colonização Europeia da África Subsariana no Século XX [Reflections on the European Colonization of Sub-Saharan Africa in the 20th Century]. Boletim da Academia internacional da Cultura Portuguesa, 35, 141-162. 
Amaral, I. (2009a). Nótulas históricas sobre os primeiros tempos da Academia das Ciências de Lisboa [Historical notes on the early days of the Lisbon Academy of Sciences]. Texto policopiado e difundido, 33 p. +3 figuras.

Amaral, I. (2009b). O sonho português das minas de prata em Cambambe (Angola) [The Portuguese dream of the silver mines in Cambambe (Angola)]. In M. Correia (Ed.), Do Kunene a Cabinda. História e estórias de Angola. IV Raid Kwanza Sul [From Kunene to Cabinda. History and stories of Angola. IV Raid Kwanza Sul] (pp. 187-191). Lisboa e Luanda: Pangeia e Chá de Caxinde.

Amaral, I. (2009c). Sobre culturas e Intercâmbios culturais [About cultures and cultural exchanges]. Boletim da Academia Internacional da Cultura Portuguesa, 36, 51-66.

Amaral, I. (2010). Reflexões de um Geógrafo em torno do tema 'Memória e História. A construção das Identidades' [Reflections of a Geographer on the theme 'Memory and History. The construction of Identities']. Luanda: IV Encontro Internacional sobre História de Angola, 39 p. policopiadas.

Amaral, I. (2012a). Estudos Preliminares de Inéditos juvenis de José Correia da Serra. A propósito do 'Catalogue Raisonné des Voyageurs de ma Bibliothèque (1769) [Preliminary Studies of juvenile novels by José Correia da Serra. On the 'Catalog Raisonné des Voyageurs de ma Bibliothèque (1969)]. Lisboa: Edições Colibri.

Amaral, I. (2012b). Nótulas históricas sobre os primeiros tempos da Academia das Ciências de Lisboa [Historical lectures on the early days of the Lisbon Academy of Sciences]. Lisboa: Edições Colibri.

Amaral, I. (2012c). As Bíblias e outras Raridades das Colecções de Frei Manuel do Cenáclo. Da sua existência na Biblioteca da Academia das Ciências de Lisboa [Bibles and other rarities from the collections of Frei Manuel do Cenáclo. On its existence in the Library of the Academy of Sciences of Lisbon]. Lisboa: Edições Colibri.

Amaral, I. (2012d). As Cidades: símbolos da Associação de Política, Economia e Cultura. Base para uma sessão com debate, curso de pós-graduação em Urbanismo U.C.P. [The Cities: symbols of the Association of Politics, Economy and Culture. The basis of a debate, postgraduate course in Urbanism U.C.P]. 56 p. policopiadas.
Amaral, I. (2013a). Estudos Preliminares de Inéditos Juvenis de José Correia da Serra. A propósito dos Zibaldone di Materie Diverse I a IV (1767) [Preliminary Studies of Juvenile Unpublished by José Correia da Serra. On the subject of the Zibaldone di Materie Diverse I to IV (1767)]. Lisboa: Edições Colibri.

Amaral, I. (2013b). Cidades na África Subsariana no século XXI, como partes do Sul Global. Cidade da Praia (Santiago, Cabo Verde) [Cities in sub-Saharan Africa in the 21st century, as parts of the Global South. City of Praia (Santiago, Cape Verde)]. Centro de Investigação em Desenvolvimento Local e Ordenamento do Território, Universidade de Cabo Verde, 38 p. policopiadas + Anexo Fotográfico com 26 imagens a cores.

Amaral, I. (2013c). Cidades na África Subsariana no século XXI, como partes do Sul Global [Cities in sub-Saharan Africa in the 21st century, as parts of the Global South]. CIDLOT, Praia, 38 p. policopiadas.

Amaral, I. \& Amaral, A. (1984a). A viagem dos pombeiros angolanos Pedro João Baptista e Amaro José entre Mucari (Angola) e Tete (Moçambique), em princípios do século XIX, ou a história da primeira travessia da África central [The trip of the Angolan Pombeiros Pedro João Baptista and Amaro José between Mucari (Angola) and Tete (Mozambique) in the early 19th century, or the history of the first crossing of central Africa]. Garcia de Orta, Série de Geografia, 9(1-2), 17-58.

Amaral, A. \& Amaral, I. (1984b). Bibliografia científica de Orlando Ribeiro [Scientific bibliography of Orlando Ribeiro]. Lisboa: Centro de Estudos Geográficos.

Amaral, I. \& Amaral, A. (1985a). Geografia das regiões tropicais [Geography of tropical regions]. (Colecção de textos comentados) Garcia de Orta, Série de Geografia, 10(1-2), 41-58.

Amaral, I. \& Amaral, A. (1985b). A Utopia e Thomas More: uma obra e um homem para a eternidade [Utopia and Thomas More: a work and a man for eternity]. In F. Moser (Ed.), Miscelânea de Estudos dedicados a Fernando de Mello Moser [Collection of Studies dedicated to Fernando de Mello Moser] (pp.65-86). Lisboa: Comissão Científica do Departamento de Estudos Anglo-Americanos da Faculdade de Letras de Lisboa. 
Anselmo, A. (1997). Estudos de História do Livro Antigo [Historical Studies of the Antique Book]. Lisboa: Guimarães editores.

Defos Du Rau, J. (1960). Lî̀le de la Réunion. Étude de Géographie Humaine [Reunion Island. A Study of Human Geography]. Bordeaux: Institut de Géographie.

Martins, J. V. (2007). Histórias de Livros para a História do Livro [Histories of Books to the History of the Book]. Lisboa: Fundação Calouste Gulbenkian.

Lasserre, G. (1961). La Guadeloupe. Étude géographique

[The Guadeloupe. Geographic study]. Vol. 2. Bordeaux : Union Française d'Impression.
Ribeiro, O. (1954). A Ilha do Fogo e as suas erupções [The Island of Fogo and its eruptions]. Col. "Memórias”, - Série Geográfica, 1954. Lisboa: Junta de Investigações do Ultramar.

Ribeiro, O., Feio, M., \& Amaral, I. (1961). Nota preliminar acerca do relevo de Angola entre os rios Zaire e Loge [Preliminary note on the relief of Angola between the rivers Zaire and Loge]. Garcia de Orta, 9(3), 509-514.

Tenreiro, F. (1961). A Ilha de São Tomé [The Island of São Tomé]. LXXIII estampas. - Memórias (2a Série). Lisboa: Junta de Investigações do Ultramar. 